\title{
British Military Hospital Dharan: The range, mode of presentation and management of malignancies presenting to the department of surgery during 1985-86.
}

\author{
Lt Col J M Ryan FRCS(Eng), RAMC \\ Consultant in Surgery \\ ${ }^{*}$ British Military Hospital Dharan HQ Brig Nepal BFPO 4.
}

\begin{abstract}
SUMMARY: British Military Hospital Dharan provides the surgeon with an opportunity, unparalleled anywhere in the United Kingdom to observe and manage a range of malignancies. The historical and contemporary reasons for this are outlined. The paper illustrates the military hospital experience and mode of presentation of a wide range of malignant conditions treated during the tour. Differences from United Kingdom practice are noted and where known, the reasons for this are discussed. Problems in diagnosis, treatment and continuing care, unique to a practice of this kind, are highlighted. The training potential of a hospital of this nature for future military surgeons is discussed.
\end{abstract}

\section{Introduction}

British Military Hospital Dharan is a 70 bed general hospital situated in the Himalayan foothills of East Nepal. Opened in 1960 to provide medical care for British military personnel, their families, Gurkha pensioners and potential recruits, it quickly extended its role and began treating local, non-entitled villagers. At the time of writing the hospital had become virtually the sole provider of Western style hospital medicine for the people of East Nepal and was a reference centre for a diverse group of aid agencies, including The Save the Children Fund, The Britain Nepal Medical Trust and the Overseas Development Agency ${ }^{1}$. This has resulted in a continuing increase in clinical workload and an increase also in presentation of late and neglected disease. As awareness of the hospital's existence spread patients walked or were carried ever increasing distances, sometimes over many weeks, to reach help. An inate suspicion of western style medicine among the more isolated hill dwellers results in patients presenting as a last resort; local traditional healers having been consulted in the first instance ${ }^{2}$.

These factors have had a undoubted effect on the incidence and mode of presentation of all conditions seen and treated at the hospital. In surgical clinics these factors translate into startling and visually impressive clinical presentations of a type now rarely seen in the United Kingdom.

Patients with malignant disease formed a small but interesting group. Marked differences in the incidence compared to the expected incidence of such conditions in United Kingdom practice were noted. There were differences too in the timing of presentation. Many were in great distress and beyond the scope of surgery alone, some were beyond medical aid.

Other factors which influenced practice were a constant limitation of beds and other resources, the absence in the country of a radiotherapy service and the limited availability of chemotherapy. Of particular interest was the presentation to the single handed surgeon of conditions which in the West would be seen in Specialist departments, gynaecological, head and neck and paediatric malignancies being typicalo examples.

\section{Disease Incidence}

The incidence rate for an illness is defined as the number of illnesses or spells of illness beginning; or the number of people becoming sick in a specified time overo the numbers exposed or at risk at the mid point of a period (eg, one year) multiplied by $\mathrm{C}$, this being ao convenience factor and usually equal to 100,000 of ag defined population at risk. In a country without national census and with no health statistics, neither this nor any other statistical rate (prevalence and mortality rates are examples) can be used. Military Hospital statistics are available and, within the limitations defined, may be used for comparison with United Kingdom practice. Table 1 lists the small group who were accepted for treatment having been referred to surgical clinics.

During the period under review 3,899 patients were seen in surgical clinics of whom only 85 were recorded as presenting with malignant disease suitable for investigation and treatment. This figure cannot be used as a reflection of the real incidence of malignant disease in Nepal. It does not include patients with malignant disease presenting to general practitioner clinics not referred further because of the extent of their condition and for whom no figures are available. Not recorded either are large numbers of patients seen in both medical and surgical outpatients who, by virtue of late presentation, were not accepted for management and were sent home with a supply of opiates. Despite this,

\footnotetext{
* Now Senior Lecturer in Military Surgery, Royal Army Medical College and Consultant Surgeon, C D E, Porton Down, Salisbury and Princess Alexandra Hospital, RAF Wroughton, Swindon, Wilts.
} 
Table 1

Patients with malignant disease accepted for treatment from surgical clinics Oct 85-Nov 86. Classification after Anderson \& Kissane

\begin{tabular}{|c|c|c|}
\hline \multicolumn{3}{|l|}{ Buccal cavity and nasopharynx } \\
\hline Tongue & 3 & (Inoperable - to India for DXT) \\
\hline Salivary gland (parotid) & 2 & \\
\hline Post natal space & 3 & (Biopsy only - to India for DXT) \\
\hline Maxillary antrum & 1 & \\
\hline \multicolumn{3}{|l|}{ Digestive organs } \\
\hline Oesophagus & 3 & \\
\hline Stomach & 9 & ( 3 inoperable) \\
\hline Large bowel & 3 & (2 inoperable) \\
\hline Pancreas & 1 & (Triple bypass) \\
\hline \multicolumn{3}{|l|}{ Respiratory tract } \\
\hline Lung & 8 & (Bronchoscopy only) \\
\hline \multicolumn{3}{|l|}{ Bone tissue and skin } \\
\hline Bone & 4 & \\
\hline Connective tissue & 4 & \\
\hline Skin & 15 & \\
\hline Breast & 3 & ( 2 inoperable) \\
\hline \multicolumn{3}{|l|}{ Genital organs } \\
\hline Uterus & 1 & \\
\hline Ovary & 5 & (4 inoperable) \\
\hline Prostate & 1 & \\
\hline $\begin{array}{l}\text { Penis } \\
\text { Pen }\end{array}$ & 4 & \\
\hline \multicolumn{3}{|l|}{ Urinary organs } \\
\hline Kidney & 2 & (1 inoperable) \\
\hline \multicolumn{3}{|l|}{ Endocrine } \\
\hline Thyroid & 2 & \\
\hline \multicolumn{3}{|l|}{ Lymphomas } \\
\hline Hodgkin's & 2 & \\
\hline Non-Hodgkin's & 5 & \\
\hline Unclassified or no diagnosis & 4 & \\
\hline All sites & & 85 \\
\hline
\end{tabular}

the true incidence of patients with malignant disease arriving at the hospital and seeking help was very low. Patients presenting with traumatic, inflammatory, infective and congenital conditions were in the majority ${ }^{1}$. In marked contrast, malignant disease in Western society is second only to cardiovascular disease as a cause of death and accounts for about $25 \%$ of all deaths under the age of $75^{3,4}$.

\section{Cancer incidence-Geographic factors}

Cancer risk is related to environmental and genetic factors, the former being more influential. It is noteworthy that migrant groups appear to loose their native predisposition to certain types of cancer but acquire the risks of cancer associated with their new environment ${ }^{3}$. Gurkha soldiers, pensioners and their families, although not migrants in the true sense of the word, reflect this changing predisposition, possibly resulting from relative affluence. Affluence has lead to a change in life style resulting in enhanced longevity compared to other Nepalis. An ironic result of this is the emergence of diseases rarely encountered elsewhere in Nepal; carcinoma of lung, oesophagus, stomach and large bowel are the best examples. It is interesting to note that of 40 cholecystectomies for calculous disease $\stackrel{2}{\approx}$ during the year under review 35 were on pensioner's or $\stackrel{\square}{\mathbb{\perp}}$ ex-soldier's wives ${ }^{1}$.

The ten most common sites for cancer in England and Wales is reported annually by the office of population censuses and surveys. Table 2 gives the results for $1980^{5}$. There is no equivalent document for the Indian subcontinent. Mould, however provides information from which crude comparisons can be drawn ${ }^{4}$. He regards the Indian subcontinent as a high risk area for tumours of lip, oral cavity, pharynx, salivary glands, $\mathbb{D}$ liver, cervix uteri and penis. The region would appear to be a low risk area for many other malignancies, some of which feature prominently in United Kingdom practice. These include cancer of large bowel, pancreas, breast, lung, corpus uteri, lymphoma and leukaemia.

These differences are not too surprising when $ᄋ$ differing environmental factors are noted. Anecdotal $D$ indications are that male life expectancy in the hillo region of East Nepal is $42 / 43$ years with females $\frac{\bar{N}}{\text {. }}$ surviving $2 / 3$ years longer. Low life expectancy would o certainly account for the scarcity of some malignancies $N$ 
Table 2

The ten most common cancer sites registered in England and Wales in 1980

\begin{tabular}{lrlr}
\hline Males & Females & \\
\hline All sites & $100 \%$ & All sites & 92,988 \\
Lung & $28 \%$ & Breast & $100 \%$ \\
Skin (not melanoma) & $11 \%$ & Skin (not melanoma) & $23 \%$ \\
Prostate & $8 \%$ & Lung & $\mathbf{1 0 \%}$ \\
Stomach & $7 \%$ & Colon & $\mathbf{9 \%}$ \\
Bladder & $6 \%$ & Stomach & $5 \%$ \\
Colon & $6 \%$ & Ovary & $5 \%$ \\
Rectum & $5 \%$ & Rectum & $5 \%$ \\
Pancreas & $3 \%$ & Uterine cervix & $4 \%$ \\
Oesophagus & $2 \%$ & Uterine body & $4 \%$ \\
Kidney \& Urinary (not bladder) & $2 \%$ & Pancreas & $3 \%$ \\
Other & $22 \%$ & Other & $24 \%$ \\
\hline
\end{tabular}

seen during the review period, large bowel malignancy being a typical example. A curious exception to this trend is carcinoma of tongue. In England and Wales this tumour is excessively rare before the age of 55 years. Its incidence then rises sharply. It remains, however, a rare tumour with an incidence of 1.4 per 100,000 population of newly diagnosed cases of cancer in 1980 . (The rate for carcinoma of bronchus and lung in men for the same period was 112 per $\left.100,000^{5}\right)$. Brookes and McKelvie have reported that carcinoma of the tongue probably accounts for $20 \%$ of all malignancies seen in India 6 These marked differences in incidence and age at presentation are due to cultural and socio-economic factors unique to the Indian subcontinent. These include the chewing of betel nut, often mixed with lime and tobacco, the use of tobacco and alcohol in combination which may commence before the teens in Nepali hill males and very poor oral hygiene. Dietary deficiency is probably an additional factor. It is noteworthy that dietary deficiency leading to hunger is probably the principal cause of betel nut chewing in the first instance; such chewing is said to relieve hunger pangs. The early onset of tobacco use may also account for the apparent prevalence of severe peripheral vascular disease seen in young men in the region. Another lesion, common in Nepal and occurring in a younger age group when compared to England and Wales, is carcinoma of the penis. Its incidence in England and Wales is similar to carcinoma of the tongue ${ }^{5}$. The majority of Nepalis are Hindu or Hindu/Buddhist and are not circumcised. This, coupled to very poor hygiene, an endemic problem in the hills, probably accounts for its apparent high incidence.

\section{Mode of presentation - General features:}

The common modes of presentation, different only from our practice by extent and multiplicity of signs, are listed at Table 3. Carcinoma of large bowel presented, as expected, infrequently and was characterised by wasting and a visible mass rather than intestinal obstruction.

Obstruction, when seen, was invariably due to abdominal tuberculosis and settled on conservative management. Oesophageal and gastric malignancies appeared to be common in pensioners; however mosto presented late with cachexia, ascites and palpabled masses from either the primary lesion or due to ${ }^{+}$. secondary deposits in liver and lymph nodes. Many were inoperable. Connective tissue tumours, often in the young, presented with an incidence probably similar to? England and Wales but were invariably characterised by their extent (Fig 1). 'Curative' resection was neve possible and even surgical palliation was impossible in a few. Presentation with extensive metastatic disease waso equally common, a hunt for the primary lesion ofter being of academic interest only and in such cases was rarely undertaken. Two salivary gland tumours were treated, both arising in the parotid; one, a pleomorphic adenoma in a twelve year old girl, the second was a very large acinous cell tumour in a 72 year old male. The father of a Gurkha pensioner, he presented having

\section{Table 3}

The most common physical signs illicited at the time of presentation in patients with malignant disease
Cachexia
Ascites
Dysphagia
Jaundice
Abdominal Mass
Lymph Node Metastases
Skin Lesions/Ulceration
Haemorrhage/Anaemia
Pain
Haematemesis
Haemoptysis
Paraplegia
Any Combination of the Above 
the natural mother. The reason for his skin colouring remains unexplained. A hill farmer, his condition was obviously related to his fair skin being constantly exposed to ultra violet radiation. In his regard he presented an impossible problem. The presenting lesion

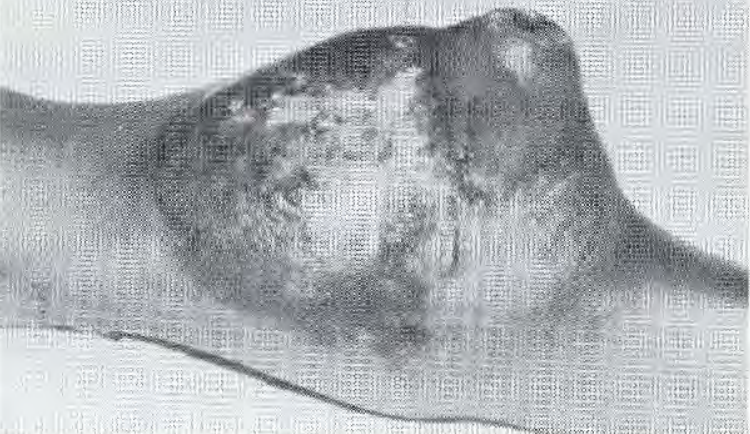

Fig 1. Neglected osteosarcoma of femur in a 16 year old girl.

trekked for two weeks to reach the hospital. He gave a 20 year history of a mass in the left parotid with a recent rapid increase in size (Fig 2). It is noteworthy that he had repeatedly consulted local healers. Patients with carcinoma of lip, tongue and oropharynx were seen commonly but were rarely accepted for surgical treatment. The following typical case history illustrates the reasons for this. A 37 year old ex-soldier presented, having trekked for a week. He complained of an ulcer on his tongue, onset probably one year before presentation. Local applications by traditional healers failed to give relief hence he reluctantly left his smallholding and family in the hills to seek help. Examination revealed an obvious carcinoma of tongue which had extended deeply to involve the floor of the mouth and backwards involving the fauces. He was in great pain and had marked dysphagia. His tumour was inoperable and he was referred to the North India University clinic at Patna having been given a cash sum from Brigade funds to cover his travel costs. Presentation with extensive lymphadenopathy, usually cervical, was very common. Most were of tuberculous origin but reticuloses presented from time to time and concerned the surgeon only from the point of view of tissue biopsy. Skin malignancies, often of great size, presented in almost every clinic. A delightful octogenarian pensioner living in the hills and who had fought on the North West Frontier presented with a huge epithelioma of the scalp (Fig 3). Quite unconcerned he presented because of the smell. Wide excision and skin grafting yielded a satisfactory result. One week after his discharge his elderly friend and neighbour presented with an almost identical lesion. Two other patients with skin tumours were noteworthy. The first, a 20 year old white skinned non-albino Nepali presented with a $10 \mathrm{~cm}$ fungating squamous carcinoma on the ankle. He was covered in freckles and many of these had become ulcerated. He was a blue eyed blond man with a typical dark skinned mother who presented with him and insisted that she was

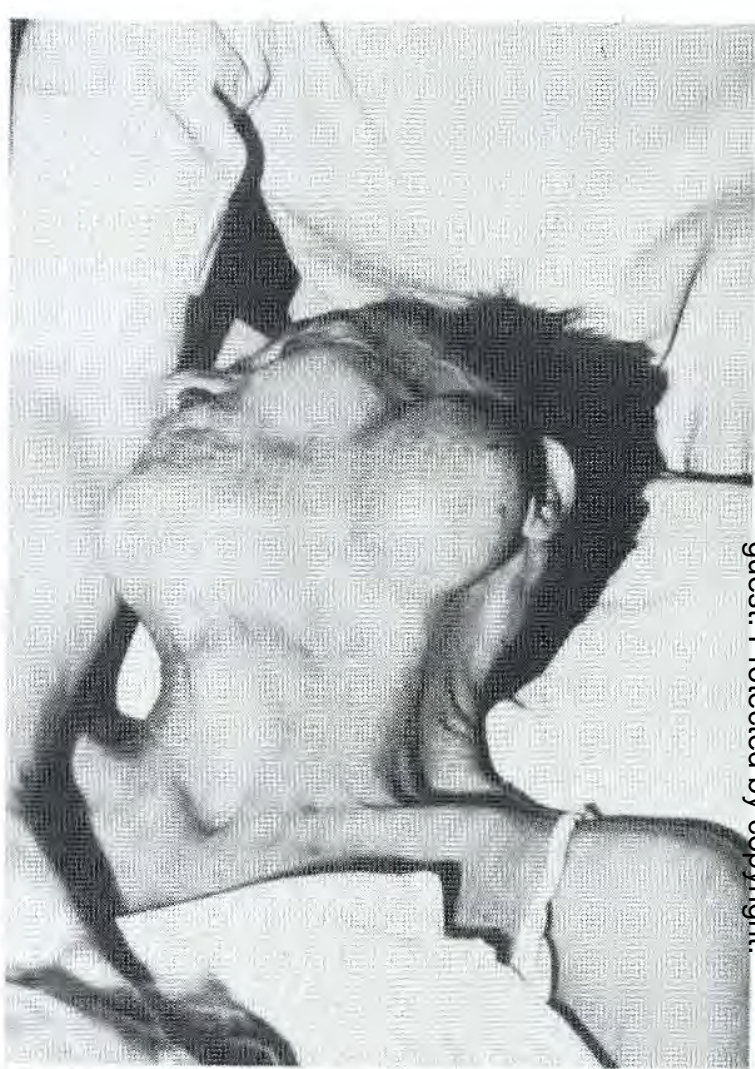

Fig 2. An acinous cell tumour left parotid of 20 year duration.

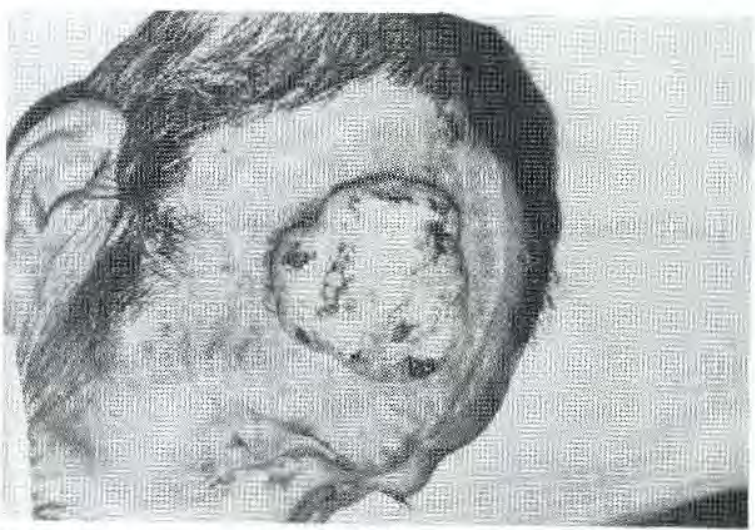

Fig 3. An extensive epithelioma in an octogenarian pensioner.

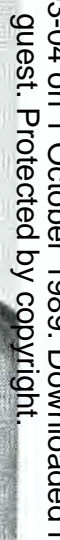


was easily dealt with by wide excision and skin grafting. However, he presented repeatedly during the year with new malignant lesions. The second young male, a 15 year old, presented with a fungating lesion replacing most of his left foot (Fig 4). This resulted in a Symes amputation of the forefoot, histology revealing a fibrosarcoma.

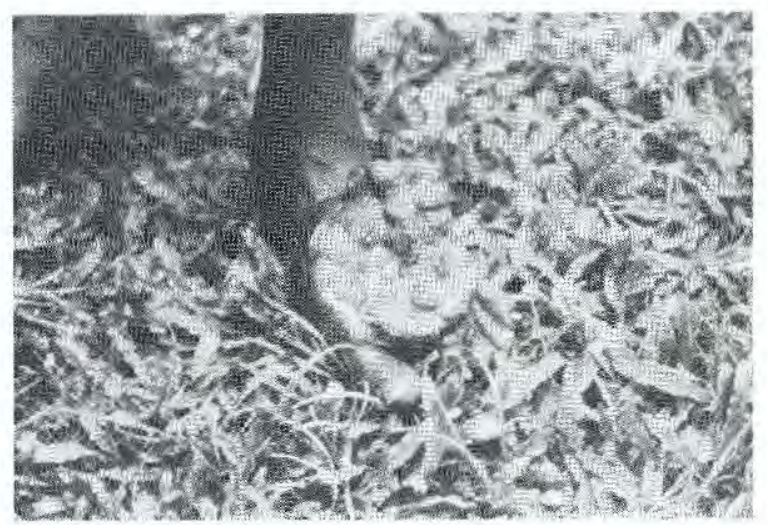

Fig 4. A fibrosarcoma on the dorsum of left foot in a hill farmer.

A more radical amputation might have been more appropriate but such a procedure for a young hill farmer would have been disastrous. A below knee amputation would have left him without a future and probably an outcast.

Nepali hill people were very reticent about undressing for examination. The nursing staff regularly found patients bathing in their pyjamas. A tragic consequence of this extreme modesty was a failure to present with disease involving the breasts or genitalia until symptoms became intolerable. Two case historics well illustrate this point. A 30 ycar old pensioner's wife and a 40 year hill farmer were seen consecutively in one clinic. The lady had a painful fungating carcinoma of breast, the man a bleeding and ulcerating carcinoma of penis with multiple fistulae (Figs $5 \& 6$ ). Both were characterised by the extent of their disease which made adequate management impossible. They presented with intractable pain and bleeding. An additional feature was the appalling smell compounding their misery. All had extensive nodal disease in addition to primary lesions. They rapidly succumbed.

This section concludes with two case presentations which typified surgical practice in Nepal. A young and apprehensive hill woman presented with her one year old son complaining of his loss of appetite and drowsiness. The attending Nepali general practitioner enquired about a massive lesion noted by him to be replacing most of the child's right hand (Fig 7). Mother expressed surprise and could not understand how this lesion could cause the child's systemic upset. Rather reluctantly she came to surgical clinic where his haemoglobin was found to be $2.9 \mathrm{gr} \%$. On questioning

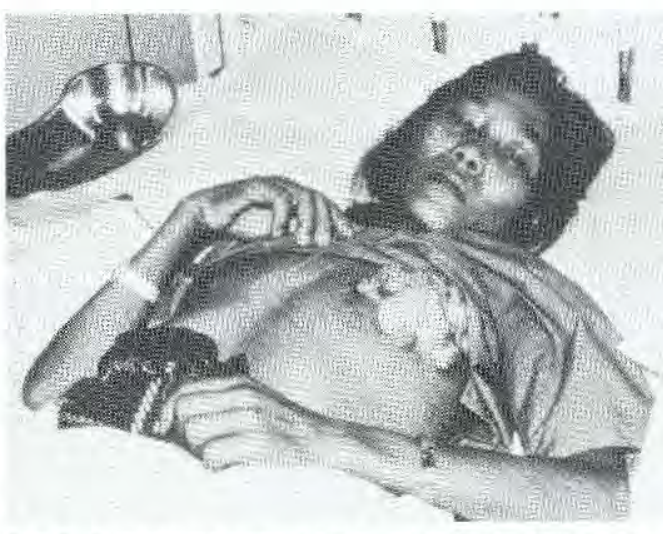

Fig 5. Fungating carcinoma replacing left breast.

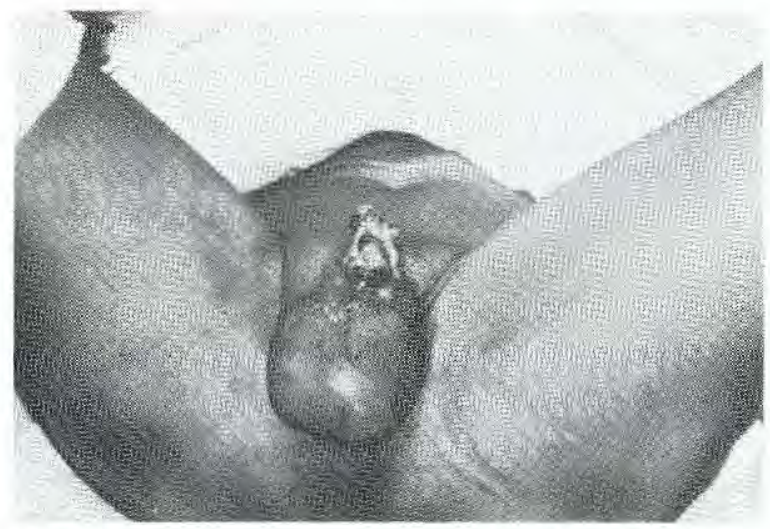

Fig 6. Extensive carcinoma of penis with fistulae.

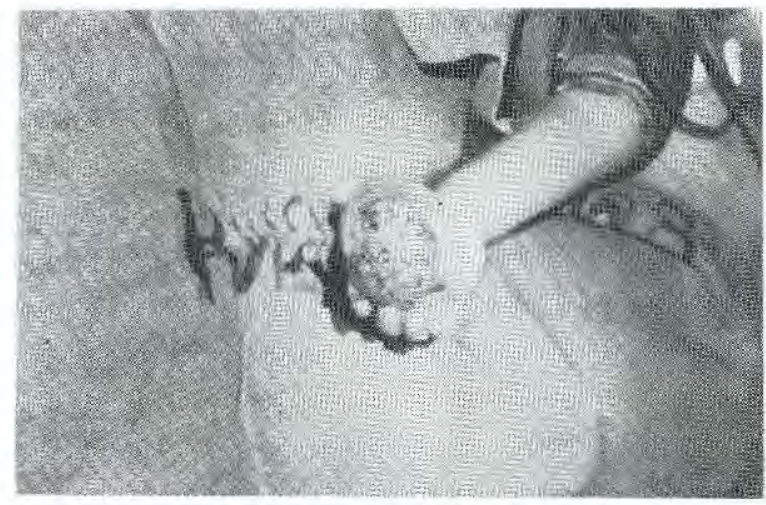

Fig 7. Infantile fibrosarcoma of the hand in a one year old child. 
she did admit noticing slight but continous bleeding from the hand over a six month period. The lesion was an obvious tumour and much to mothers distress an amputation was carried out. Histology revealed an infantile fibrosarcomi. Finally, a single 22 year old girl presented with urinary incontinence. Clinical examination revealed a pelvis full of tumour which was presenting at the introitus (Fig 8). At EUA, tumour was seen to have replaced the vagina and was infiltrating the bladder and urethra, hence her incontinence. She was catheterised and biopsies taken, histology revealed a lymphoma. She followed a rapid downhill course and was sent home to dic with a liberal supply of opiates prescribed for pain.

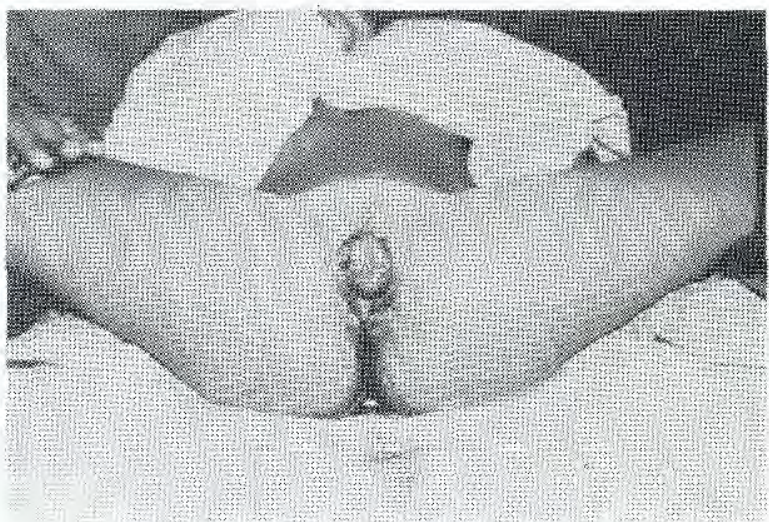

Fig 8. Extensive pelvic Iymphoma presenting at the introitus.

\section{Aspects of Management:}

Many of these patients only came following the onset of intractable pain or continuing bleeding. Adequate management was usually impossible not least because of their disease but also because of limited beds and resources. Admission to the wards for such patients was rarcly possiblc; most were sent home with strong analgesics. Some with less advanced discase were referred to the North India University Medical Clinic at Patna, 100 miles south of Dharan where, under a reciprocal medical arrangement. Nepalis were cntitled to free treatment. Because of poverty and social circumstances few ever undertook this journey. In carefully selected cases funds from the hospital budget or from the Brigade of Gurkhas welfare fund made such journcys possible. A locally available radiotherapy servicc would revolutionise management, particularly for tumours of oro-pharynx and genitalia which would seem to be common and usually of squamous origin. A limited chemotherapy supply allowed palliation for patients with advanced lymphomas and leukaemias (such paticnts were managed by the consultant physician) and resulted in marked amelioration of symptoms for the few that could bc accepted for treatment. All of these factors greatly influenced the choice of patient accepted for treatment. However, with large numbers presenting at each clinic errors of judgement were probably made in selection and rejection of cases.

\section{Discussion:}

The range of tumours presenting to the British Military Hospital in Dharan has been described and comparison made with Western practice within the constraints discusscd carlicr. Modes of presentation and aspects of management have been outlined. The changing pattern of disease in pensioners and their families has been noted, it is interesting to observe that similar trends have been reported elsewhere ${ }^{3}$. With increasing prosperity in areas of Nepal opening up to mass tourism the changing pattern of disease incidence will be doubtless reflected in other sections of the population. This has already happened in the Kathmandu valley. For most regions however, the pattern described will continue. Knowledge of such locat discase trends may help to prepare a surgeone contemplating clinical practice in Nepal or in other regions where similar conditions exist.

The tour provided a useful glimpse into the past. Table 4 lists common causes of mortality for Englando and Wales in year 1881 . Tuberculosis heads the list with 'all cancers' a poor second followed by a list of other infectious diseases. Doctors who have worked in Nepal will recognise these figures as they seem to correlate welt with the apparent discase incidence rates for Nepa today.

An important aspect of working in Dharan is the training potential. Whilst considerable training value has been obtained by a largc number of newly appointed consultants over the last 25 years it secms such a pity that such opportunities were not extended to surgeons in training. A junior surgeon working under the supervision of a senior collcague would be exposed in a very short time to a vast array of pathology presenting in gross form. The educational value of such posts for military surgeons must be immense, few remain where a military

Table 4

The six most common causes of death in England and Wales for the year 1881

\begin{tabular}{lr}
\hline \multicolumn{2}{c}{ Annual deaths per million population of both sexes } \\
\hline 1. TB & 2429 \\
2. All Cancer & 602 \\
3. Mcasles & 406 \\
4. Whooping cough & 414 \\
5. Scarlet fever & 312 \\
6. Diphtheria & 153 \\
\hline
\end{tabular}


surgeon in training may be exposed to a truly general surgical caseload. The constant demand on beds and theatre time and the need to correctly allocate time and resources provide realistic training for surgery in war. Rigid case selection was a daily experience and its correct application was crucial to the smooth running of the hospital. Although not Triage, which has a specific connotation relevant to trauma, rigid case selection imposed the sort of discipline which is necessary in the Triage setting. Military surgeons in war are required to cope with a varied and often continuing workload and without the support of specialised colleagues. They may also have to cope working alone or, at best, in small groups and often in less than ideal surroundings. Limited resources will affect what they may achieve. Working in an environment such as Dharan provides the young surgeon with an opportunity to experience conditions very similar to those in war and in this regard is probably unique. It seems appropriate to conclude by reminding ourselves that such posts provide the last bastion for that much maligned individual, the general surgeon.

\section{REFERENCES}

1. RYAN J M. British Military Hospital Dharan: Surgical Experience 1985-86 J R Army Med Corps 1988; 134: 7-15.

2. STROWBRIDGE N F and RYAN J M. Inappropriate Traditional Treatment Resulting in Limb Amputation: $J R$ Army Med Corps 1987; 133: 171-174.

3. O'Higgins N., Oncology. In Taylor S, Chisholm G D, O'Higgins $\mathrm{N}$ et al Eds. Surgical Management, Chapter 38, 569-595. Heinemann Medical Books Ltd. London: 1986.

4. Mould R F. Cancer Statistics. Adam Hilger Ltd. Bristol: 1983.

5. Cancer Statistics Registration. Office of Population Censuses and Surveys, Series MB1 No. 12. HMSO. London: 1980.

6. BROOKES G B and MCKelviE P. Tumours of the head Carcinoma of the tongue. Br J Hosp Med 1982; 28: 6-21.

\section{Acknowledgement:}

The author wishes to thank the staff of the photographic department at C D E, Porton Down for their help with preparation of the clinical photographs and Mr Stephen Cater of Trauma Section, C D E for preparing the tables.

\title{
HONORARY CONSULTANTS TO THE ARMY
}

\author{
Professor D A Warrell, MA, MD(Oxon), BCh, FRCP, \\ has been appointed Honorary Consultant in \\ Malariology to the Army with effect from 1 April 1989. \\ Professor M Irving, MSc, MD, ChM, FRCS, \\ FRCS(Ed), FICS(Hon)USA, has been appointed \\ Honorary Consultant in Surgery to the Army with effect \\ from 10 May 1989.
}

